\title{
Robert Jacob, La grâce des Juges. L'institution judiciaire et le sacré en Occident
}

Paris, Presses universitaires de France, coll. « Hors collection », 2014, $520 \mathrm{p}$.

\section{Mustapha Naïmi}

\section{(2) OpenEdition}

Journals

Édition électronique

URL : http://journals.openedition.org/assr/27385

DOI : $10.4000 /$ assr. 27385

ISSN : $1777-5825$

Éditeur

Éditions de l'EHESS

Édition imprimée

Date de publication : 1 octobre 2015

Pagination : 317

ISBN : 978-2-7132-2515-4

ISSN : 0335-5985

Référence électronique

Mustapha Naïmi, « Robert Jacob, La grâce des Juges. L'institution judiciaire et le sacré en Occident », Archives de sciences sociales des religions [En ligne], 172 I octobre-décembre, mis en ligne le 25 mai 2016, consulté le 23 septembre 2020. URL : http://journals.openedition.org/assr/27385 ; DOI : https:// doi.org/10.4000/assr.27385

Ce document a été généré automatiquement le 23 septembre 2020.

() Archives de sciences sociales des religions 


\section{Robert Jacob, La grâce des Juges. L'institution judiciaire et le sacré en Occident}

Paris, Presses universitaires de France, coll. « Hors collection », 2014, $520 \mathrm{p}$.

Mustapha Naïmi

\section{RÉFÉRENCE}

Robert Jacob, La grâce des Juges. L'institution judiciaire et le sacré en Occident, Paris, Presses universitaires de France, coll. « Hors collection », 2014, 520 p. 
1 L'ouvrage tente de comprendre le halo de sacralité qui entoure aujourd'hui encore la pratique de la justice. Il rassemble une série d'études sur la pratique du serment judiciaire et de l'ordalie dans nombre de cultures. L'ordalie est une pratique judiciaire connue des mondes anciens et médiévaux où les autorités, gardiennes de l'ordre et de la loi, invoquaient l'intervention des cieux lors du jugement de certains crimes, afin d'établir la culpabilité ou l'innocence d'un accusé. Politique et religieux y sont fortement liés: la royauté médiévale d'Orient et d'Occident possède une dimension sacrée ; le souverain, investi par les cieux de son autorité, est un souverain de première fonction veillant à maintenir l'ordre, à faire régner la justice et appliquer la loi. L'omniprésence du sacré en fait un élément clef intervenant dans les pratiques judiciaires, la guerre, la conduite morale des rois et autres dignitaires.

2 Pourtant, à considérer l'ensemble des données, celles de l'histoire occidentale et les autres, du point de vue des techniques de la procédure (et non du point de vue interne d'un système religieux déterminé à un moment donné de son histoire), la distinction est de celles qui se brouillent rapidement. Le serment est aussi à sa manière une épreuve, dont la réussite n'est pas toujours acquise. De l'ordalie à la divination, l'écart est celui qui sépare une parole que valide une épreuve de l'interprétation d'un signe, qui n'est formellement liée à aucune parole et qui, pour cette raison, ne saurait condamner ni innocenter définitivement personne. Les modes opératoires de l'une et de l'autre diffèrent en général. Un autre cas limite est le tirage au sort. À dire vrai, clore un litige, en particulier un litige sur des biens, en tirant au sort les lots de chacun est une idée fort commune. Il n'est pas nécessaire de croire au caractère magique du tirage pour convenir que l'on réglera ainsi la querelle.

3 C'est à partir du $\mathrm{XII}^{\mathrm{e}}$ siècle seulement que les juges des rois, des villes, de l'Église commencèrent à s'affranchir des tâches de la médiation et de l'ordonnancement des rites pour trancher les procès de leur propre autorité. De ces transformations ont émergé les deux modèles dominants qui se sont établis au fil des siècles: celui de la common law d'Angleterre, appelé à se diffuser par-delà les mers, et le système dit "romano-canonique ", conçu par l'Église et à son usage avant de se voir transmis par elle aux États du continent européen. À la genèse de ces ordres juridiques, le jugement de Dieu avait laissé en héritage une matrice culturelle commune.

4 L'objet d'une histoire de la très longue période est moins la formation du concept de séparation des pouvoirs que celle des conditions qui l'ont rendu pensable. Les textes juridiques des constitutions n'enferment pas tout ce que les Occidentaux mettent dans cette idée. Il y entre aussi une grande part d'implicite, renvoyant à ce qui peut paraître aller de soi parce qu'en Occident, cela va de soi depuis longtemps. C'est pourquoi il ne 
suffit pas qu'un pays recopie dans la constitution qu'il se donne les modèles qu'on lui propose pour qu'aussitôt les résultats escomptés apparaissent comme par enchantement, dans toute la complexité des implications qu'ils postulent. À travers le droit international, l'Occident a entrepris aujourd'hui de donner des leçons au monde et d'universaliser sa conception de l'État de droit. Mais, ce faisant, il n'a pas pris toute la mesure du long chemin qu'il a autrefois parcouru pour y accéder et de l'effort qu'il demande à ceux à qui il propose, ou tente d'imposer, l'acculturation à ses modèles.

5 La vague des serments provisoires qui commence à inonder les enceintes judiciaires à partir du second quart du XII ${ }^{\mathrm{e}}$ siècle participe de ce mouvement. À travers elle, la fonction de juger délaisse la matérialité objective des rites décisoires pour venir s'inscrire au cœur de la subjectivité des juges. Les jurés conquièrent sur Dieu la faculté de manifester la vérité judiciaire, au prix d'une subsomption de leur conscience, qui vient occuper une sorte d'espace intermédiaire : impossible à confondre avec le divin proprement dit, mais cependant sublimé parce qu'elle est totalement engagée devant lui et tente de s'extraire, avec son aide, des faiblesses de la nature humaine. Tel fut le rôle du serment des juges dans le monde des laïcs. L'ordre ecclésiastique, en revanche, ne pouvait en ressentir le besoin. Le pouvoir de juger s'y fondait sur des rapports de pouvoir qui n'étaient pas mis en cause et sur des sacralités préexistantes, que conféraient l'ordination sacerdotale et la hiérarchie.

6 Au sortir de la mutation des XII ${ }^{\mathrm{e}}$ et XIII ${ }^{\mathrm{e}}$ siècles, la géographie judiciaire de l'Europe s'est ébauchée. Les deux grandes familles du tronc occidental sont reconnaissables. Ce fut l'occasion de faire retour sur les textes sacrés pour en proposer de nouvelles lectures. Le haut Moyen Âge avait donné le pas à l'Ancien Testament. C'est là qu'il était allé chercher le rite du sacre des rois justiciers comme les fondements scripturaires de l'ordalie christianisée. Le second Moyen Âge redonne la préférence à l'Évangile. C'était placer les juges face à un discours moral qui leur témoignait une extrême dureté. Le juge prend la place de Dieu, usurpation condamnable dans son principe mais rendue nécessaire, et aussitôt chargée d'une lourde ambivalence. Les juges deviennent euxmêmes des dieux, comme ont osé le dire les Psaumes, par métaphore peut-être, mais dans une formule dont on oubliera volontiers qu'elle l'était et que l'on sera souvent tenté de prendre au mot. La justice expose alors plus que quiconque celui qui s'y engage. L'audace de l'homme qui se fait juge, en même temps qu'elle l'érige en hommedieu, fait de lui le premier justiciable du Dieu juge.

7 D'est en ouest, les juges siègent sous le même ciel, mais ils ne le peuplent pas de la même manière et ils vivent autrement le respect qu'ils lui portent. Les monothéismes ont conçu un être omniscient, omnipotent, souverain, maître de la distinction du bien et du mal, parfait Législateur et parfait Juge. Certains d'entre eux, le judaïsme et l'islam, ont rompu le lien qu'ils étaient tentés d'instaurer avec le juge pour ne plus retenir que le Législateur. Pour les docteurs de l'islam médiéval, il n'est de savoir et de vérité que dans l'ordre légal ; l'ordre des faits est inaccessible et ne peut relever que du probable. À l'opposé, le christianisme occidental a exacerbé son lien au souverain Juge. En somme, l'opposition des symboles élémentaires auxquels chaque culture a associé sa justice, la balance occidentale et la licorne chinoise, illustre assez bien ce qui les sépare. En Occident, la justice est l'art de régler les procès, tous les procès, ce qui est la tâche de l'État. La vérité s'obtient par la mise en balance des assertions contraires, de quelque manière que se résolve leur antagonisme, et l'exigence du jugement est ressentie comme impérieuse. En Chine, la justice d'État s'est affranchie du règlement 
systématique des causes. Elle ne s'éveille que lorsqu'elle perçoit la menace d'un trouble à l'ordre et à l'harmonie. Si surgit l'animal à la corne unique, il lui faut alors le détecter, fondre sur lui et le réduire, mais avec assez de prudence pour éviter que naisse de son action un trouble plus grand. Des logiques irréductibles de l'œuvre de justice sont nées de cet écart. 